STUDI

FRANCESI

\section{Studi Francesi}

Rivista quadrimestrale fondata da Franco Simone

174 (LVIII | III) | 2014

Varia

\title{
Pontus de Tyard, Euvres complètes: Tome III. Mantice, ou Discours de la verité de Divination par Astrologie
}

\section{Dario Cecchetti}

\section{(2) OpenEdition}

1 Journals

\section{Edizione digitale}

URL: http://journals.openedition.org/studifrancesi/1115

DOI: 10.4000/studifrancesi. 1115

ISSN: 2421-5856

\section{Editore}

Rosenberg \& Sellier

\section{Edizione cartacea}

Data di pubblicazione: 1 novembre 2014

Paginazione: 581-582

ISSN: 0039-2944

\section{Notizia bibliografica digitale}

Dario Cecchetti, « Pontus de Tyard, Euvres complètes: Tome III. Mantice, ou Discours de la verité de Divination par Astrologie », Studi Francesi [Online], 174 (LVIII | III) | 2014, online dal 01 novembre 2014 consultato il 18 septembre 2020. URL : http://journals.openedition.org/studifrancesi/1115; DOI : https://doi.org/10.4000/studifrancesi. 1115

Questo documento è stato generato automaticamente il 18 settembre 2020.

\section{(c)}

Studi Francesi è distribuita con Licenza Creative Commons Attribuzione - Non commerciale - Non opere derivate 4.0 Internazionale. 


\title{
Pontus de Tyard, Euvres complètes: Tome III. Mantice, ou Discours de la verité de Divination par Astrologie
}

\author{
Dario Cecchetti
}

\section{NOTIZIA}

PONTUS DE TYARD, Euvres complètes: Tome III. Mantice, ou Discours de la verité de Divination par Astrologie, texte établi, introduit et annoté par Jean Céard, Paris, Classiques Garnier, 2014 («Textes de la Renaissance», 191), pp. 231.

1 Per quanto esistesse una buona edizione critica commentata di Mantice (a cura di Sylviane Bodkam, Genève, Droz, 1990), la pubblicazione delle Cuvres complètes di Pontus de Tyard, diretta da Eva Kushner, esigeva una nuova edizione, che viene ora egregiamente apprestata da uno specialista del rango di Jean Céard (cui dobbiamo, nelle stesse Euvres complètes, la cura del Premier curieux e del De recta nominum impositione). Il nuovo editore, che aveva già supervisionato la precedente edizione, si propone «de serrer davantage l'examen des sources déjà reconnues et de chercher de compléter l'inventaire des sources réelles de Tyard: car certaines jettent une lumière nouvelle sur la poétique et les préoccupations intellectuelles de ce dernier». In effetti, primo pregio di questa edizione è il ricco apparato di note (pp. 135-202) che cita le fonti di Tyard, spesso per esteso, permettendo così dei raffronti e delle considerazioni interessanti. E di queste fonti si serve in parte J. Céard per costruire una densa introduzione, vera monografia, che traccia la storia di Mantice, ne ricostruisce la datazione e ne illustra la valutazione che ne fecero i contemporanei, anche attraverso l'esame dei testi liminari (sia dell'edizione di Jean de Tournes del 1558 sia di quella di Galiot du Pré del 1573), testi che vengono dati in Appendice. Ma soprattutto analizza accuratamente la struttura di questo Discours, raffrontata a quella degli altri Discours di Tyard, evidenziando, all'interno delle fonti minuziosamente repertoriate, alcuni autori che rappresentano gli assi portanti della trattazione dell'autore sull'astrologia: in 
particolare, fra i classici, Luciano e Plotino; fra i moderni, Pico della Mirandola e Celio Rodigino (vera miniera di riferimenti, quest'ultimo, per la cultura rinascimentale europea, e per di più autore di cui J. Céard ha dimostrato, nelle sue edizioni, di essere uno dei migliori conoscitori). Il testo di Mantice riprodotto è quello dell'edizione dei Discours philosophiques del 1587, che presenta una serie di addizioni, alcune di una certa estensione, tutte segnalate in apparato. Il presente editore, inoltre, tiene conto e integra nel testo gli interventi fatti a mano da Tyard in una copia di sua appartenenza. Esemplare, anche, il lessico. 